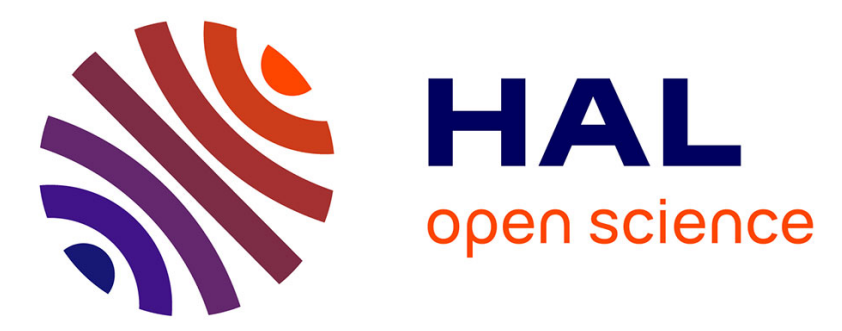

\title{
Projections of global changes in precipitation extremes from Coupled Model Intercomparison Project Phase 5 models
}

\author{
Andrea Toreti, Philippe Naveau, Matteo Zampieri, Anne Schindler, Enrico \\ Scoccimarro, Elena Xoplaki, Henk Dijkstra, Silvio Gualdi, Jürg Luterbacher
}

\section{To cite this version:}

Andrea Toreti, Philippe Naveau, Matteo Zampieri, Anne Schindler, Enrico Scoccimarro, et al.. Projections of global changes in precipitation extremes from Coupled Model Intercomparison Project Phase 5 models. Geophysical Research Letters, 2013, 40 (18), pp.4887-4892. 10.1002/grl.50940 . hal-03210263

\section{HAL Id: hal-03210263 \\ https://hal.science/hal-03210263}

Submitted on 28 Apr 2021

HAL is a multi-disciplinary open access archive for the deposit and dissemination of scientific research documents, whether they are published or not. The documents may come from teaching and research institutions in France or abroad, or from public or private research centers.
L'archive ouverte pluridisciplinaire HAL, est destinée au dépôt et à la diffusion de documents scientifiques de niveau recherche, publiés ou non, émanant des établissements d'enseignement et de recherche français ou étrangers, des laboratoires publics ou privés. 


\title{
Projections of global changes in precipitation extremes from Coupled Model Intercomparison Project Phase 5 models
}

\author{
Andrea Toreti, ${ }^{1}$ Philippe Naveau, ${ }^{2}$ Matteo Zampieri, ${ }^{3}$ Anne Schindler, ${ }^{1}$ \\ Enrico Scoccimarro, ${ }^{3,4}$ Elena Xoplaki, ${ }^{1}$ Henk A. Dijkstra, ${ }^{5}$ \\ Silvio Gualdi, ${ }^{3,4}$ and Jürg Luterbacher ${ }^{1}$ \\ Received 25 July 2013; revised 4 September 2013; accepted 6 September 2013; published 20 September 2013.
}

[1] Precipitation extremes are expected to increase in a warming climate; thus, it is essential to characterize their potential future changes. Here we evaluate eight highresolution global climate model simulations in the twentieth century and provide new evidence on projected global precipitation extremes for the 21 st century. A significant intensification of daily extremes for all seasons is projected for the middle and high latitudes of both hemispheres at the end of the present century. For the subtropics and tropics, the lack of reliable and consistent estimations found for both the historical and future simulations might be connected with model deficiencies in the representation of organized convective systems. Low intermodel variability and good agreement with high-resolution regional observations are found for the twentieth century winter over the Northern Hemisphere middle and high latitudes. Citation: Toreti, A., P. Naveau, M. Zampieri, A. Schindler, E. Scoccimarro, E. Xoplaki, H. A. Dijkstra, S. Gualdi, and J. Luterbacher (2013), Projections of global changes in precipitation extremes from Coupled Model Intercomparison Project Phase 5 models, Geophys. Res. Lett., 40, 4887-4892, doi:10.1002/grl.50940.

\section{Introduction}

[2] Exposure and vulnerability to weather and climaterelated natural hazards largely determine the severity of impacts of these extremes [IPCC, 2012]. In the context of climate change, where considerable changes in the frequency and intensity of extremes are expected, the development of adequate risk-reduction strategies and measures is crucial. Since planning requires reliable knowledge of the relevant climate phenomena, a robust characterization in terms of frequency and intensity of current and future

Additional supporting information may be found in the online version of this article.

${ }^{1}$ Climatology, Climate Dynamics and Climate Change, Department of Geography, Justus Liebig University Giessen, Giessen, Germany.

${ }^{2}$ Laboratoire des Sciences du Climat et de l'Environnement, IPSLCNRS, Gif-sur-Yvette, France.

${ }^{3}$ Centro Euro-Mediterraneo sui Cambiamenti Climatici, Lecce, Italy.

${ }^{4}$ Istituto Nazionale di Geofisica e Vulcanologia, Bologna, Italy.

${ }^{5}$ Department of Physics and Astronomy, Utrecht University, Utrecht, Netherlands.

Corresponding author: A. Toreti, Climatology, Climate Dynamics and Climate Change, Department of Geography, Justus Liebig University Giessen, Senckenbergstr. 1, DE-35390 Giessen, Germany. (andrea.toreti@ geogr.uni-giessen.de)

(C)2013. American Geophysical Union. All Rights Reserved. 0094-8276/13/10.1002/grl.50940 extreme precipitation is of great relevance. Changes in mean annual precipitation have been observed in different regions of the world, with decreasing tendencies over the tropics and subtropics of the Northern Hemisphere (NH), increases over the northern middle and high latitudes, and over the tropics and subtropics of the Southern Hemisphere (SH) [Trenberth et al., 2007; Zhang et al., 2007; Trenberth, 2011]. A widespread increase both in the frequency and intensity of daily precipitation extremes has already been identified [Alexander et al., 2006; Min et al., 2011; Westra et al., 2013], although uncertainties arising from the lack of observations at the daily scale and the interpolation procedures applied for the production of available gridded data sets affect the estimations of precipitation extremes [Trenberth et al., 2007; Chen and Knutson, 2008; Hofstra et al., 2009; O'Gorman and Schneider, 2009; Min et al., 2011; Trenberth, 2011]. In the NH, this upward tendency (that has been identified in the second half of the twentieth century) has been linked to human-induced greenhouse gases increase [Min et al., 2011].

[3] Global climate models (GCMs) still cannot adequately capture the frequency, intensity, tendency, and spatial distribution of observed precipitation extremes over large regions in the world [Sun et al., 2006; Allan and Soden, 2008; O'Gorman and Schneider, 2009; Min et al., 2011]. Global warming implies an increase of atmospheric water vapor content at a rate of about $7 \% / \mathrm{K}$, through the ClausiusClapeyron equation [Allan and Soden, 2008]. Hence, a comparable increase in extreme precipitation would be expected over the next decades [O'Gorman and Schneider, 2009; Kharin et al., 2013]. A significant reduction in return times of annual extremes of daily precipitation (20 year return level) has been globally projected for different radiative forcing scenarios for the late 21 st century with large intermodel disagreement in the tropics [Kharin et al., 2013].

[4] Here we evaluate the simulated daily precipitation extremes in the twentieth century assuming stationary processes [e.g., Scoccimarro et al., 2013]. This implies that the ability of the models to reproduce the observed tendencies in specific regions of the world is not considered. Furthermore, we provide for the first time a comprehensive global assessment of seasonal future changes in daily precipitation extremes identifying regions where both consistency (i.e., models agreement) and reliability (i.e., goodness of fit of the applied statistical model) are achieved.

\section{Data and Methods}

[5] Simulations for the period 1966-2099 were retrieved from the Coupled Model Intercomparison Project Phase 5 
[Taylor et al., 2012]. Eight models with a horizontal atmospheric resolution higher than $1.5^{\circ}$ were chosen (Table $\mathrm{S} 1$ in the supporting information) and daily precipitation data were retrieved. As for the projections (2006-2099), the high emissions scenario (representative concentration pathway, RCP) RCP8.5 and the mid-range mitigation emissions scenario RCP4.5 [Moss et al., 2010] were selected. With respect to observations, an equivalent global highresolution daily precipitation data set covering the historical period 1966-2005 does not exist. Therefore, freely available high-resolution regional products were retrieved. As shown in Table $\mathrm{S} 2$, these gridded products have a spatial resolution of $0.25^{\circ}\left(0.05^{\circ}\right.$ over Australia). They do not cover the entire world, but they provide a very good coverage of the Euro-Mediterranean region, northern Eurasia, the Middle East, Asia, Australia, and North America. Concerning northern Eurasia and the Middle East, the two associated gridded data sets have a limited overlapping with the EuroMediterranean data set. Further details as well as maps of the covered regions can be found in the respective publications [Higgins et al., 2000; Jones et al., 2009; Haylock et al., 2008; Yatagai et al., 2012] and the related websites (Table S2).

[6] Since the eight GCMs have different resolutions and grids, and precipitation is highly dependent on the spatial scale, all daily gridded values were remapped onto a common grid with the coarsest resolution of $1.5^{\circ}$ by applying a conservative remapping procedure [Chen and Knutson, 2008]. By applying the same procedure, in order to allow for a comparison between gridded observations and model simulations for the historical period 19662005 , observations were remapped to the common grid of the models.

[7] As for the characterization of the extremes and their changes in the 21 st century, we compare the two 40 year time periods 2020-2059 and 2060-2099 with the historical period. The length of the two periods ensures an adequate data amount for the statistical inference that is known to be data demanding for extremes. In order to assess the goodness of fit of the statistical model (hereafter called as reliability), stationary processes within each 40 year period were assumed.

[8] The analysis was performed in the frame of Extreme Value Theory by applying a Peaks Over Threshold approach [Davison and Smith, 1990]. In this context, the distribution of excesses over a high threshold (here set as the 90th percentile) can be modeled by using the Generalized Pareto (GP) family, i.e.,

$$
\begin{array}{ll}
H_{\sigma, \xi}(y)=1-\{1+(\xi y / \sigma)\}^{-1 / \xi}, & \xi \neq 0 \\
H_{\sigma, \xi}(y)=1-\exp (-y / \sigma), & \xi=0
\end{array}
$$

where $\sigma>0, y \geq 0$ when $\xi \geq 0$ and $y \in[0,-\sigma / \xi]$ when $\xi<0$. The two parameters $\sigma$ and $\xi$ are called scale and shape parameters, respectively. As soon as an estimation for both parameters is available ( $\hat{\xi}$ and $\hat{\sigma})$, the return level $z_{R}$ (i.e., the value that is expected to be exceeded on average once every $R$ years, here 50 ) can be estimated by

$$
z_{R}=u+\hat{\sigma} \hat{\xi}^{-1}\left[\left(R \zeta_{u}\right)^{\hat{\xi}}-1\right]
$$

where $u$ is the chosen threshold and $\zeta_{u}$ is the intensity of the Poisson process which is assumed to describe the occurrence of the excesses. Concerning the parameters estimation and in order to avoid numerical problems connected with optimization procedures, we applied the Generalized Probability Weighted Moments (GPWM) method (see the Appendix A) [Diebolt et al., 2007].

[9] The goodness of fit of the estimation was tested by a modified Anderson-Darling statistic [Luceño, 2006, and references therein], i.e.,

$$
A=n \int_{-\infty}^{\infty}\left[H(y)-F_{n}(y)\right]^{2} \cdot[1-H(y)]^{-1} \mathrm{~d} y
$$

where $n$ denotes the number of excesses, $H$ is the assumed theoretical distribution (here Generalized Pareto), and $F_{n}$ is the empirical distribution function. Since the parameters of the distribution $H$ were not known, the asymptotic distribution of $A$ and thus the critical values (at the 0.95 level) for the test were also unknown. As a consequence of applying the GPWM method, the covariance of the Gaussian process to which the integrand of $A$ asymptotically converges cannot be approximated. Thus, the critical values for the test were obtained by using a bootstrap procedure [Babu and Rao, 2004].

[10] In brief for the bootstrap procedure, let $y_{1}, \ldots, y_{n}$ be the excesses and $\hat{\sigma}$ and $\hat{\xi}$ the estimated parameters. Then, $m$ additional samples (in this exercise 1000) can be generated from $H_{\hat{\sigma}, \hat{\xi}}$ and the $A$ statistic can be computed $m$ times by estimating the shape and the scale from the generated $m$ samples. The critical values for the test can be derived from the calculated $m$ values of $A$.

[11] In order to perform an intermodel comparison with respect to observations in the historical period 1966-2005, Taylor diagrams were used for the estimated return level fields [Taylor, 2001].

\section{Results}

[12] Changes in precipitation extremes are presented in terms of very high risk events, i.e., 50 year return levels (values that are expected to be exceeded on average once every 50 years) derived by the inferred distributions.

[13] In the historical period (Figure 1), a reliable characterization of daily extreme precipitation cannot be achieved for larger areas of the world, where an estimation of the return levels cannot be obtained. This is the case during boreal winter for a belt elongated over the subtropics and tropics of the $\mathrm{NH}$ and the oceanic areas west of the three continents of the SH. In boreal summer, unreliable estimations (i.e., failing the goodness-of-fit test) are found mainly over the eastern North Pacific, north-eastern Africa, and Arabian Peninsula as well as a large part of the Mediterranean basin and the eastern North Atlantic, eastern South Pacific, and north central Australia. A similar spatial pattern is also identified for spring and autumn (not shown). Lack of reliability corresponds to areas characterized by higher positive values of the shape parameter (not shown) and therefore strongly heavy-tailed Generalized Pareto distributions. Although spatial differences do exist, this correspondence is a common feature of seven out of eight models and could be connected with the parameterization of convection in regions receiving smaller amounts of seasonal precipitation [Dai, 2006], poorly represented land- and ocean-atmosphere interactions as well as deficiencies in the representation 
a
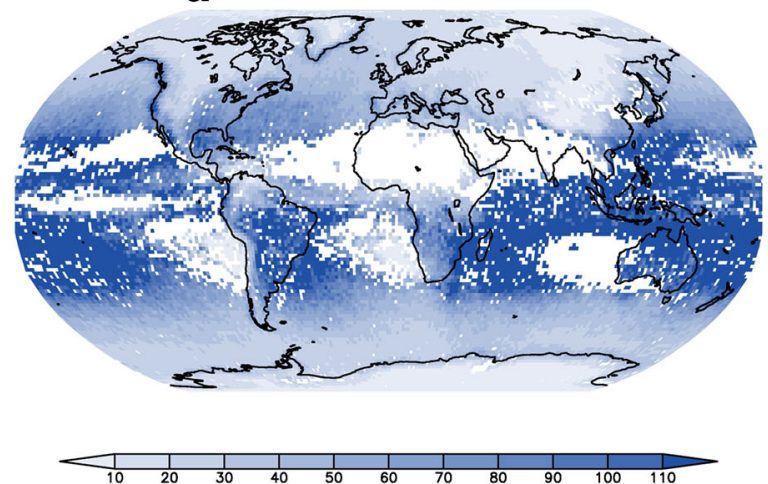

b

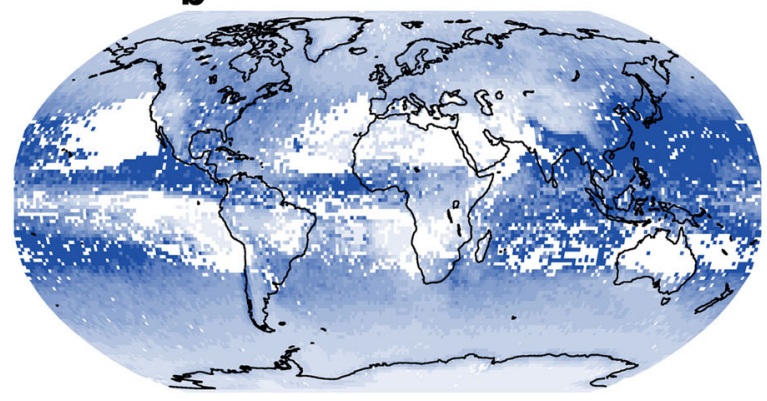

C

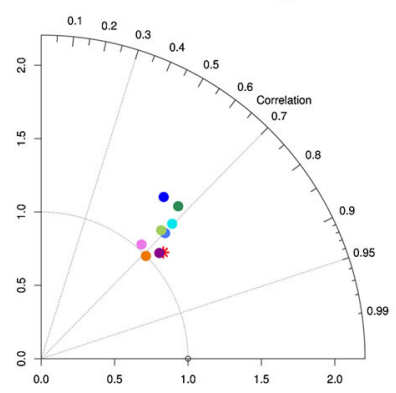

CMCC

- HadCC

d

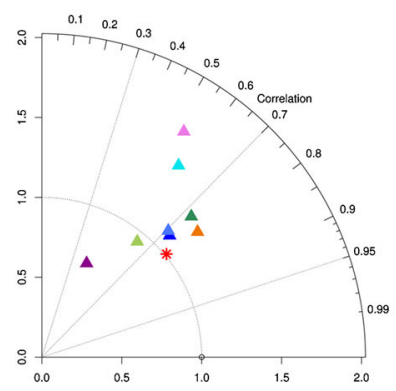

e

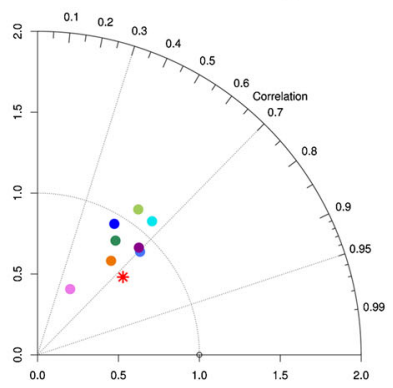

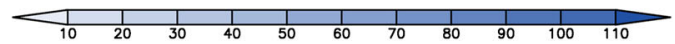

Figure 1. Ensemble mean 50 year return levels (mm) estimated for the period 1966-2005 in boreal (a) winter and (b) summer. Blue colored areas identify grid points where at least $75 \%$ of the models pass the goodness-of-fit test (reliable points). Taylor diagrams for estimated 50 year return levels in winter and summer over (c, d) northern Eurasia and (e, f) North America. The full symbols denote models with at least $75 \%$ of reliable grid points in the region.

(position and shape) of the Intertropical Convergence Zone [Huang et al., 2004; Dai, 2006; Richter and Xie, 2008; Good et al., 2009].

[14] For the middle and high latitudes, six out of eight models show a spatially homogeneous tail behavior with slightly negative and positive values of the shape parameter (not shown). This means that the probability of precipitation extremes either has a finite upper bound or decreases approximately exponentially or slightly slower toward zero. Nevertheless, a glance at the individual simulations reveals remarkable intermodel differences as well as areas with a larger probability of higher extremes. In the EuroMediterranean area, northern Eurasia, and North America, the simulations show lower intermodel variability and higher correlation with the observations in boreal winter (Figures 1 and S1). Conversely, for Australia, southern Asia, and the Middle East, all seasons are characterized by larger intermodel variability and lower correlation with the observations (Figures S1 and S2).

[15] For the period 2020-2059, both scenarios reveal reliable and consistent changes only for scattered areas in the middle and high latitudes of both hemispheres (Figures 2 and S3). A similar global pattern with regional differences is estimated for the other seasons (not shown). It is worth noting that the intensity reduction over the northern tropical
Atlantic is strongly seasonally dependent as it almost disappears in boreal summer and is less pronounced in spring and autumn.

[16] Toward the end of the 21st century (2060-2099), a similar pattern but with more pronounced changes compared to the middle of the century is projected under the RCP8.5 scenario. For the RCP4.5 scenario, for which the radiative forcing stabilizes in the second half of the $21 \mathrm{st}$ century, changes in extremes are less pronounced. Consistent and reliable increases of precipitation extremes are obtained for all seasons over the middle and high latitudes of both hemispheres mainly for the RCP8.5 scenario. In the $\mathrm{SH}$, the spatial pattern of consistent and reliable areas does not show a marked seasonal dependence. In the $\mathrm{NH}$ within the zone showing consistency and reliability, different areas can be highlighted for each season (potentially connected with sea ice changes [e.g., Budikova, 2009; Screen et al., 2013]), for instance, northern Eurasia in boreal winter and the North Pacific and northwestern Atlantic/Arctic Ocean in boreal summer (Figure 2). Meridional differences are clearer in the zonal means (Figures 3 and S4). They show more pronounced increases over the high latitudes of both hemispheres in all seasons, with the exception of the $\mathrm{NH}$ in the mid-century boreal summer, associated with larger intermodel variability. Over the $\mathrm{SH}$, 

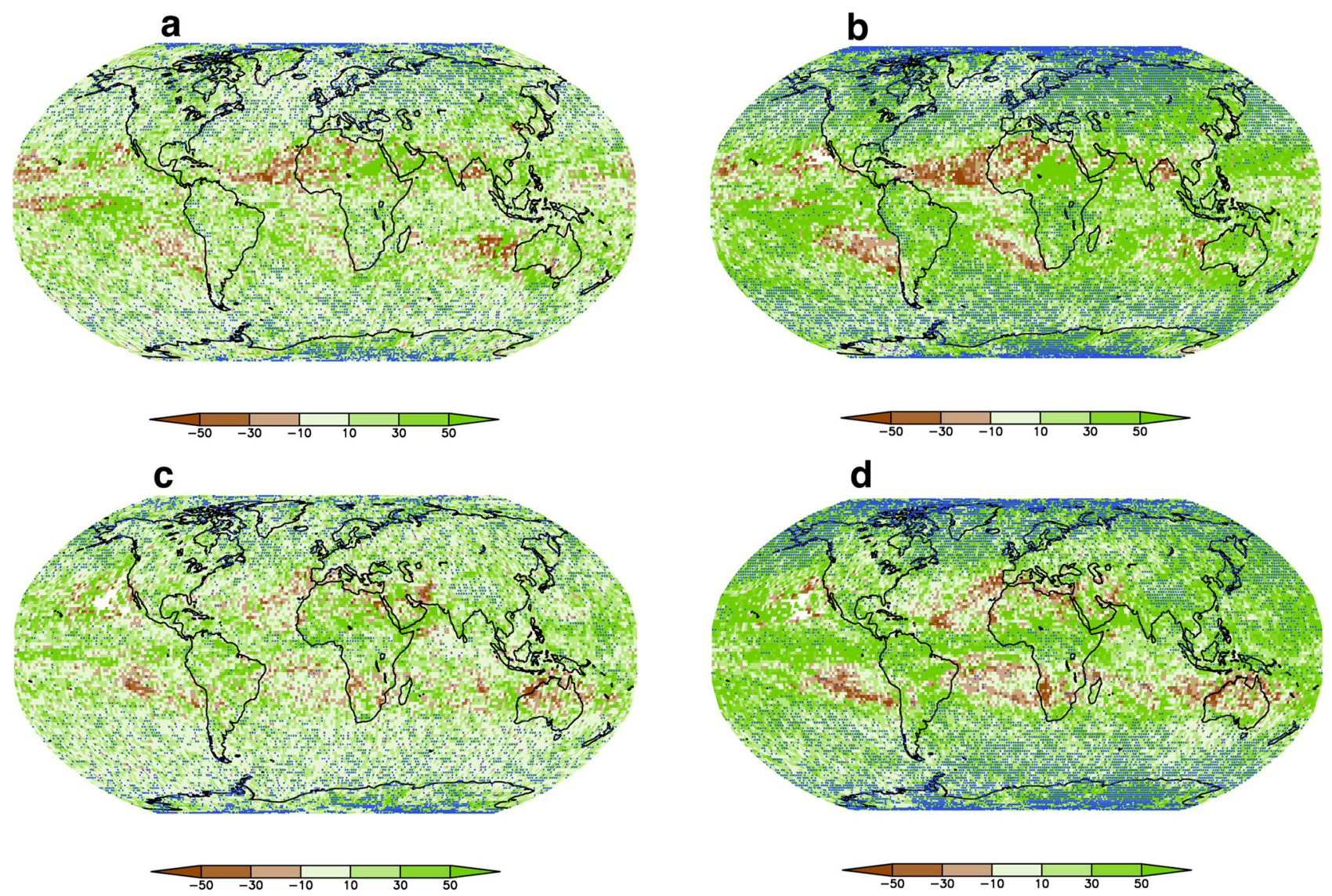

Figure 2. Ensemble mean changes of the estimated 50 year return levels (\%) with respect to the period 1966-2005, under the RCP8.5 scenario for winter (a) 2020-2059 and (b) 2060-2099 and summer (c) 2020-2059 and (d) 2060-2099. Blue dots mark grid points where at least $75 \%$ of the models pass the goodness-of-fit test and agree on the sign of the estimated changes.

a sharp decrease in the estimated positive changes from the high to the middle latitudes is evident in all seasons and, with the exception of the austral winter, followed by a strong increase toward the low latitudes. Over the $\mathrm{NH}$, the poleward meridional increase of the estimated positive changes is almost continuous in boreal winter (Figure 3 ) and autumn (not shown), while a stepwise poleward increase is projected for summer (Figure 3) and spring (not shown).
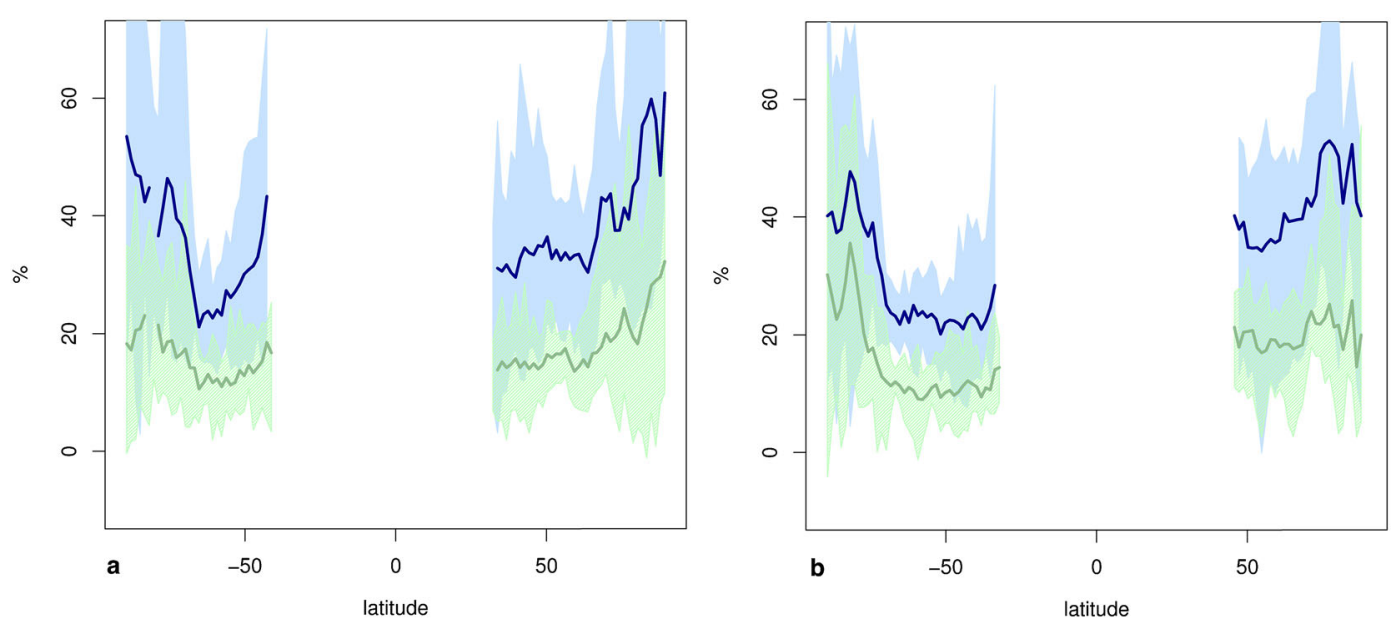

Figure 3. Zonal mean changes of the estimated 50 year return levels (\%) with respect to the period 1966-2005 in (a) winter and (b) summer under the RCP8.5 scenario. Blue and green lines represent the ensemble mean for the periods 2020-2059 and 2060-2099, respectively. Blue and green shaded areas show the intermodel variability for the periods 2020-2059 and 2060-2099, respectively. The ensemble mean and the intermodel variability are plotted only when at least six models out of eight provide at least $75 \%$ of reliable grid points for the zonal mean. 


\section{TORETI ET AL.: CMIP5 PRECIPITATION EXTREMES}

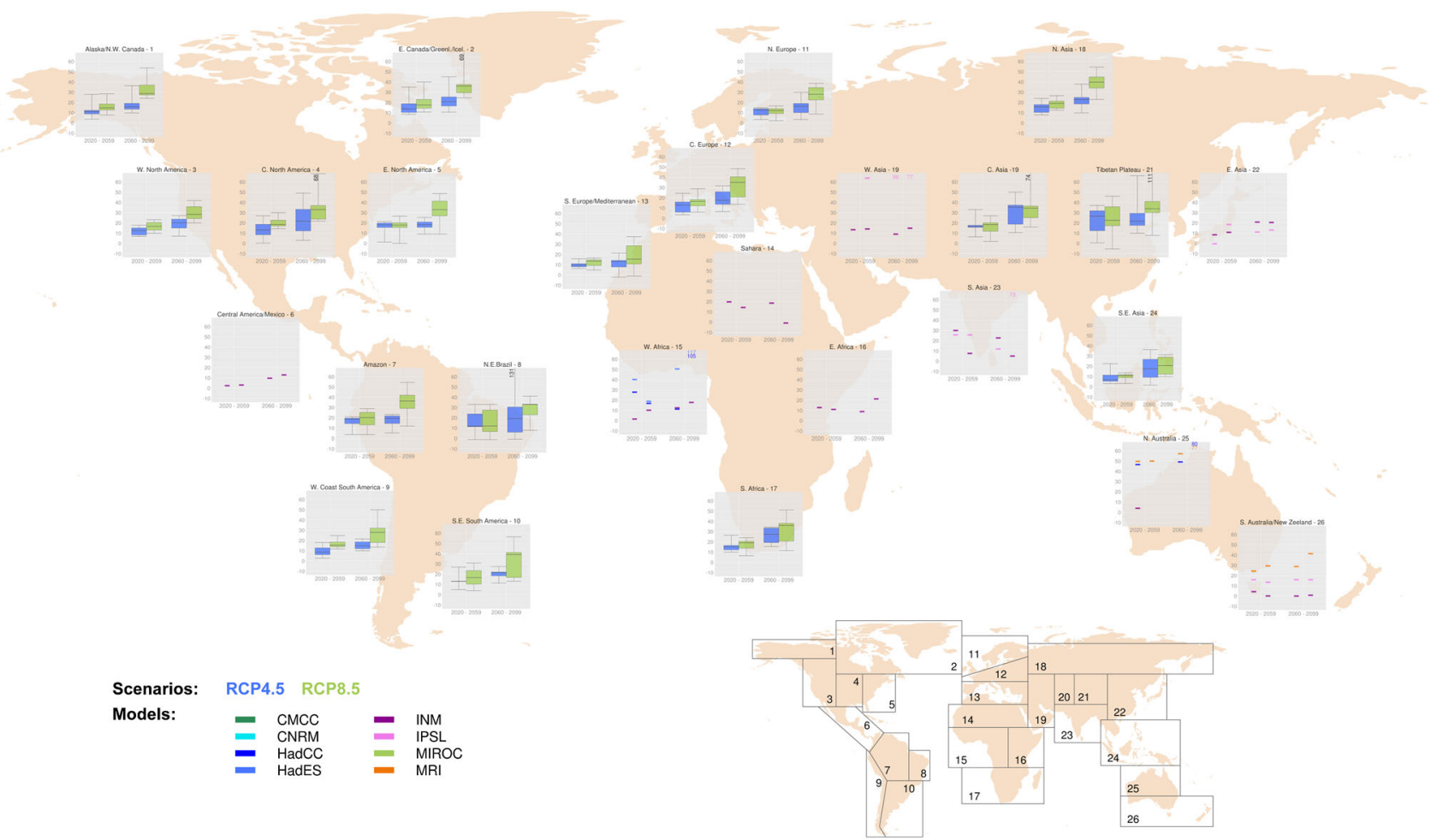

Figure 4. Regional mean changes of winter 50 year return levels (\%) in the periods 2020-2059 and 2060-2099 (RCP4.5 and RCP8.5 scenarios) with respect to the reference 1966-2005. Regional means are derived for each model using only land grid points. Boxplots are drawn when at least four models contribute with a minimum of $75 \%$ of reliable land points in the region. The black line is the median of the regional means; the whiskers of the boxplots represent the maximum and the minimum of the areal means. Pointplots are drawn when the above conditions are not satisfied.

Stronger hemispheric differences (Figure 3) are estimated over the high latitudes for RCP8.5 at the second half of the century that are most prominent in summer $(11 \%$ difference between the $\mathrm{NH}$ and $\mathrm{SH}$ spatial means) and autumn (15\% difference between the $\mathrm{NH}$ and $\mathrm{SH}$ spatial means). The largest changes at the second half of the century are found over the high latitudes of the NH for autumn (45\%) and for spring in the SH (39\%). In the same period (20602099), the mean changes over the midlatitudes are highest in the NH autumn (37\%) and the SH summer (30\%). No reliable assessment can be made for the subtropical-tropical regions (Figure 3). The identified increase of extremes for the 21 st century (although seasonally and regionally dependent) is higher than previously estimated for annual extremes [Kharin et al., 2013]. The effect of stabilization of the radiative forcing in the RCP4.5 scenario is evident in Figure S4, showing less pronounced differences between the two periods 2020-2059 and 2060-2099 compared to the RCP8.5 scenario.

[17] In order to gain a better insight into the regional changes, 26 land areas [IPCC, 2012] were selected and the intermodel variability of the regional means is provided in Figures 4 and S5-S7. Remarkable seasonal and regional differences are evident among the 26 land areas. Reliable extremes characterization can be made for $62 \%(65 \%)$ of the land areas in boreal winter (summer) and for $88 \%(85 \%)$ of the areas in spring (autumn). For some areas, reliability shows a clear seasonal dependency (e.g., southern Europe), while this is not the case for regions such as northern Europe and northern Asia. Finally, it is evident from the results that the regional averages show a better agreement between models.

\section{Discussion}

[18] In the tropics, the identified lack of reliability and consistency in extreme precipitation could be associated with a deficiency in the representation of upward velocities that seems to introduce large differences in climate models output, an underestimation of the response to global warming [Allan and Soden, 2008; O'Gorman and Schneider, 2009] as well as with model difficulties in reproducing processes based on organized convective systems [Zhang, 2005; Benedict and Randall, 2007]. Conversely in the middle and high latitudes, where large-scale processes play an important role [O'Gorman and Schneider, 2009], reliable and consistent results seem to be coherent with the Clausius-Clapeyron constraint and dynamically linked to the polar warming amplification [Schlosser et al., 2010; Jaiser et al., 2012; Francis and Vavrus, 2012; Screen and Simmonds, 2013]. Further research is however necessary to provide detailed evidence for this connection.

[19] At the regional level, models show a better agreement on the projected increase of return levels over land, although large variability affects the estimated seasonal changes over specific areas (e.g., eastern Asia in summer). Finally, it is worth to point that for some areas such as the Indian Monsoon region, where models deficiencies were also identified by Hasson et al. [2013] and Sperber et al. [2013], reliable estimations cannot be achieved. 


\section{Appendix A: The GPWM Method}

[20] The GPWM for the Generalized Pareto distribution are defined by

$$
\mu_{\omega}=E\left\{Y \omega\left(1-H_{\sigma, \xi}(Y)\right)\right\}
$$

where $E$ denotes the expected value and $\omega$ is a continuous function null (and with right derivative) at 0 . An estimator of $\mu_{\omega}$ is given by [Diebolt et al., 2007]

$$
\hat{\mu}_{\omega, n}=\int_{0}^{\infty} W\left(1-F_{n}(x)\right) \mathrm{d} x
$$

where $n$ represents the number of excesses, $F_{n}$ denotes the empirical distribution function of the excesses, and $W$ is the primitive of $\omega$. For applications (as in the current exercise), a good choice for the function $\omega$ is $\omega(x)=x^{r}$ with $r=1,1.5$. This implies that $\mu_{\omega}=\mu_{r}$ can be estimated by

$$
\hat{\mu}_{r}=n^{-1} \sum_{i=1}^{n} Y_{(i)} \cdot\left[(n-i) n^{-1}\right]^{r}
$$

where $Y_{(i)}$ represents the ordered sample of the excesses. Finally, the estimated parameters are provided by using the following equalities, replacing $\mu_{1}$ and $\mu_{1.5}$ with their estimates:

$$
\begin{gathered}
\sigma=\left(2.5 \mu_{1.5} \mu_{1}\right) \cdot\left(2 \mu_{1}-2.5 \mu_{1.5}\right)^{-1} \\
\left.\xi=\left[4 \mu_{1}-(2.5)^{2} \mu_{1.5}\right]\right] \cdot\left(2 \mu_{1}-2.5 \mu_{1.5}\right)^{-1}
\end{gathered}
$$

This approach is valid for $\xi \in(-1,1.5)$.

[21] Acknowledgments. A.T., J.L., E.X., and P.N. acknowledge support from the EU-FP7 ACQWA project (212250). A.T. acknowledges DFG (grant TO829/1-1). J.L. and A.S. are also supported by the project Climate Change and Extreme Weather in Hesse-Analysis of observation data and ensemble projections for the 21st century funded by the Hessian Centre on Climate Change and Geology (HLUG). We thank F. Albrecht for computational support and P. Fraschetti for data retrieving and computational support. We acknowledge the World Climate Research Programme's Working Group on Coupled Modeling for model simulations. We thank EU-FP6 project ENSEMBLES, NOAA/OAR/ERL PSD, APHRODITE project, and the Bureau of Meteorology Australia for gridded observations. We thank two anonymous reviewers for their comments and suggestions.

[22] The Editor thanks two anonymous reviewers for their assistance in evaluating this paper.

\section{References}

Alexander, L. V., et al. (2006), Global observed changes in daily climate extremes of temperature and precipitation, J. Geophys. Res., 111, D05109, doi:10.1029/2005JD006290.

Allan, R. P., and B. J. Soden (2008), Atmospheric warming and the amplification of precipitation extremes, Science, 321, 1481-1484.

Babu, G. J., and C. R. Rao (2004), Goodness-of-fit tests when parameters are estimated, Sankhya, 66, 63-74.

Benedict, J. J., and A. D. Randall (2007), Observed characteristics of the MJO relative to maximum rainfall, J. Atmos. Sci., 64, 2332-2354.

Budikova, D. (2009), Role of Arctic sea ice in global atmospheric circulation: A review, Global Planet. Change, 68, 149-163.

Chen, C. T., and T. Knutson (2008), On the verification and comparison of extreme rainfall indices from climate models, J. Climate, 21, $1605-1621$.

Dai, A. (2006), Precipitation characteristics in eighteen coupled climate models, J. Climate, 19, 4605-4630.

Davison, A. C., and R. L. Smith (1990), Models for exceedances over high thresholds, J. Roy. Stat. Soc. B Met, 52, 393-442.

Diebolt, J., A. Guillou, and I. Rached (2007), Approximation of the distribution of excesses through a generalized probability-weighted moments method, J. Stat. Plan. Infer., 137, 841-857.
Francis, J. A., and S. J. Vavrus (2012), Evidence linking Arctic amplification to extreme weather in mid-latitudes, Geophys. Res. Lett., 39, L06801, doi:10.1029/2012GL051000.

Good, P., J. A. Lowe, and D. P. Rowell (2009), Understanding uncertainty in future projections for the tropical Atlantic: Relationships with the unforced climate, Clim. Dyn., 32, 205-218.

Hasson, S., V. Lucarini, and S. Pascale (2013), Hydrological cycle over South and Southeast Asian river basins as simulated by PCMDI/CMIP3 experiment, Earth Sys. Dynam., 4, 199-217.

Haylock, M. R., et al. (2008), A European daily high-resolution gridded data set of surface temperature and precipitation, J. Geophys. Res., 113, D20119, doi:10.1029/2008JD010201.

Higgins, R. W., et al. (2000), Improved United States precipitation quality control system and analysis, NCEP/Climate Prediction Center Atlas.

Hofstra, N., et al. (2009), Testing E-OBS European high-resolution gridded data set of daily precipitation and surface temperature, J. Geophys. Res., 114, D21101, doi:10.1029/2009JD011799.

Huang, B., P. S. Schopf, and J. Shukla (2004), Intrinsic ocean-atmosphere variability of the tropical Atlantic ocean, J. Climate, 17, 2058-2077.

IPCC (2012), Managing the Risks of Extreme Events and Disasters to Advance Climate Change Adaptation. A Special Report of Working Groups I and II of the Intergovernmental Panel on Climate Change, C. B. Field et al. (eds), Cambridge Univ. Press, New York.

Jaiser, R., et al. (2012), Impact of sea ice cover changes on the Northern Hemisphere atmospheric winter circulation, Tellus A, 64, 11595 , doi:10.3402/tellusa.v64i0.11595.

Jones, D. A., W. Wang, and R. Fawcett (2009), High-quality spatial climate data sets for Australia, Aust. Meteorol. Ocean. J., 58, 233-248.

Kharin, V. V., et al. (2013), Changes in temperature and precipitation extremes in the CMIP5 ensemble, Climatic Change, 119(2), 345-357, doi: $10.1007 / \mathrm{s} 10584-013-0705-8$.

Luceño, A. (2006), Fitting the generalized Pareto distribution to data using maximum goodness-of-fit estimators, Comput. Stat. Data An., 51, 904-917.

Min, S. K., et al. (2011), Human contribution to more intense precipitation extremes, Nature, 470, 378-381.

Moss, R. H., et al. (2010), The next generation of scenarios for climate change research and assessment, Nature, 463, 747-756.

O'Gorman, P. A., and T. Schneider (2009), The physical basis for increases in precipitation extremes in simulations of 21 st-century climate change, Proc. Nat. Acad. Sci. U.S.A., 106, 14,773-14,777.

Richter, I., and S. P. Xie (2008), On the origin of equatorial Atlantic biases in coupled general circulation models, Clim. Dyn., 31, 587-598.

Screen, J. A., and I. Simmonds (2013), Exploring links between Arctic amplification and mid-latitude weather, Geophys. Res. Lett., 40 959-964, doi:10.1002/grl.50174.

Screen, J. A., et al. (2013), Atmospheric impacts of Arctic sea-ice loss, 1979-2009: Separating forced change from atmospheric internal variability, Clim. Dyn., doi:10.1007/s00382-013-1830-9.

Schlosser, E., et al. (2010), Characteristics of high precipitation events in Dronning Maud Land, Antarctica, J. Geophys. Res., 115, D14107, doi:10.1029/2009JD013410.

Scoccimarro, E., et al. (2013), Heavy precipitation events in a warmer climate: Results from CMIP5 models, J. Climate, doi:10.1175/JCLI-D12-00850.1

Sperber, K. R., et al. (2013), The Asian summer monsoon: An intercomparison of CMIP5 vs. CMIP3 simulations of the late 20th century, Clim Dyn., doi:10.1007/s00382-012-1607-6.

Sun, Y., et al. (2006), How often does it rain? J. Climate, 19, 916-934.

Taylor, K. E. (2001), Summarizing multiple aspects of model performance in a single diagram, J. Geophys. Res., 106, 7183-7192.

Taylor, K. E., R. J. Stouffer, and G. A. Meehl (2012), An overview of CMIP5 and the experiment design, B. Am. Meteorol. Soc., 93, 485-498.

Trenberth, K. E. (2011), Changes in precipitation with climate change, Clim. Res., 47, 123-138.

Trenberth, K. E., et al. (2007), Observations: Surface and atmospheric climate change, in Climate Change 2007: The Physical Science Basis. Contribution of Working Group I to the Fourth Assessment Report of the Intergovernmental Panel on Climate Change, edited by S. Solomon et al., pp. 235-336, Cambridge Univ. Press, New York.

Westra, S., L. V. Alexander, and F. W. Zwiers (2013), Global increasing trends in annual maximum daily precipitation, J. Climate, 26, 3904-3918.

Yatagai, A., et al. (2012), APHRODITE: Constructing a long-term daily gridded precipitation data set for Asia based on a dense network of rain gauges, B. Am. Meteorol. Soc., 93, 1401-1415.

Zhang, C. (2005), Madden-Julian Oscillation, Rev. Geophys., 43, RG2003, doi:10.1029/2004RG000158.

Zhang, X., et al. (2007), Detection of human influence on twentieth-century precipitation trends, Nature, 448, 461-466. 